\title{
Article \\ Diphlorethohydroxycarmalol Isolated from Ishige okamurae Exerts Vasodilatory Effects via Calcium Signaling and PI3K/Akt/eNOS Pathway
}

\author{
Yu An Lu ${ }^{1}$, Yunfei Jiang ${ }^{1}$, Hye-Won Yang ${ }^{1}$, Jin Hwang ${ }^{1}$, You-Jin Jeon $1,2, * \mathbb{D}$ and Bomi Ryu ${ }^{1, *(\mathbb{D})}$ \\ 1 Department of Marine Life Science, Jeju National University, Jeju 63243, Korea; \\ annie.lu1213@gmail.com (Y.A.L.); jiangyunfei0310@aliyun.com (Y.J.); koty221@naver.com (H.-W.Y.); \\ ghkdwls9280@naver.com (J.H.) \\ 2 Marine Science Institute, Jeju National University, Jeju 63333, Korea \\ * Correspondence: youjin2014@gmail.com (Y.-J.J.); ryu.bomi@gmail.com (B.R.)
}

Citation: Lu, Y.A.; Jiang, Y.; Yang, H.-W.; Hwang, J.; Jeon, Y.-J.; Ryu, B. Diphlorethohydroxycarmalol Isolated from Ishige okamurae Exerts Vasodilatory Effects via Calcium Signaling and PI3K/Akt/eNOS Pathway. Int. J. Mol. Sci. 2021, 22, 1610. https://doi.org/10.3390/ ijms22041610

Academic Editor: Sunoh Kim Received: 14 December 2020 Accepted: 3 February 2021 Published: 5 February 2021

Publisher's Note: MDPI stays neutral with regard to jurisdictional claims in published maps and institutional affiliations.

Copyright: (c) 2021 by the authors. Licensee MDPI, Basel, Switzerland. This article is an open access article distributed under the terms and conditions of the Creative Commons Attribution (CC BY) license (https:/ / creativecommons.org/licenses/by/ $4.0 /)$.

\begin{abstract}
Nitric oxide (NO) is released by endothelial cells in the blood vessel wall to enhance vasodilation. Marine polyphenols are known to have protective effects against vascular dysfunction and hypertension. The present study is the first to investigate how diphlorethohydroxycarmalol (DPHC) isolated from Ishige okamurae affects calcium levels, resulting in enhanced vasodilation. We examined calcium modulation with the well-known receptors, acetylcholine receptor (AchR) and vascular endothelial growth factor 2 (VEGFR2), which are related to NO formation, and further confirmed the vasodilatory effect of DPHC. We confirmed that DPHC stimulated NO production by increasing calcium levels and endothelial nitric oxide synthase (eNOS) expression. DPHC affected AchR and VEGFR2 expression, thereby influencing transient calcium intake. Specific antagonists, atropine and SU5416, were used to verify our findings. Furthermore, based on the results of in vivo experiments, we treated $T g(f l k: E G F P)$ transgenic zebrafish with DPHC to confirm its vasodilatory effect. In conclusion, the present study showed that DPHC modulated calcium transit through AchR and VEGFR2, increasing endothelial-dependent NO production. Thus, DPHC, a natural marine component, can efficiently ameliorate cardiovascular diseases by improving vascular function.
\end{abstract}

Keywords: Diphlorethohydroxycarmalol; Calcium; VEGFR2; Acetylcholine receptor; NO production; Vasodilation

\section{Introduction}

Hypertension is a medical condition characterized by persistently high pressure on the blood vessels [1]. The higher the pressure, the more the heart has to pump to overcome the resistance from blood vessels due to the blood pressure [2]. Therefore, vasodilation plays a vital role in preventing hypertension. Nitric oxide (NO) release by endothelial cells in the blood vessel wall has been reported to improve vascular tone [3]. Thus, it is now widely accepted that NO, along with the endothelium-derived relaxing factor [4], exerts vasodilatory and antiproliferative effects to maintain vascular homeostasis. NO is synthesized by the endothelial nitric oxide synthase (eNOS), which is activated by blood shear-stress and agonists such as acetylcholine [5].

Additionally, NO production by eNOS activation is mediated by the release of calcium ions from subsarcolemmal storage sites through two distinct mechanisms: (i) shearing stress on the vascular endothelium generated by the blood flow induces calcium release and the subsequent eNOS activation associated with the phosphoinositide 3-kinase (PI3K)/protein kinase B (Akt)-dependent signaling pathway [6]; (ii) endothelial receptors recognizing the vascular endothelial growth factor (VEGF) or acetylcholine (Ach) stimulate calcium release and subsequent NO production [5,7]. Conversely, endothelium dysfunction causing reduced intracellular $\left[\mathrm{Ca}^{2+}\right]$ concentration and eNOS-derived NO levels can contribute 
to hypertension [8]. Therefore, NO homeostasis by endothelial cell regulation is critical for modulating the vascular tone [9]. Thus, the investigation of NO-based therapeutics is important in hypertension prevention.

Marine algae have been widely used as medicinal foods that harbor several vascular health-improving properties, such as antioxidative, anti-inflammatory, and antithrombotic properties, as well as the ability to modulate NO bioavailability [10]. Ishige okamurae (IO) is an edible brown alga widely distributed throughout the temperate coastal zone of East Asia [11]. Several studies have suggested the beneficial effect of IO in ameliorating cardiovascular conditions by inhibition of angiotensin I-converting enzyme (ACE) and maintenance of vascular homeostasis in vivo and in vitro [12]. Furthermore, diphlorethohydroxycarmalol (DPHC) is a major phenolic compound isolated from IO [11]. The strong ability of DPHC to regulate vascular endothelial cells and improve cardiovascular disease has been previously reported [13]. However, the underlying molecular mechanisms involved in DPHC-mediated vasodilation in endothelial cells remain unknown. Hence, the present study aimed to evaluate the effects of DPHC on calcium levels and NO production, and consequently, vasodilation.

\section{Results}

\subsection{Cytotoxicity of DPHC and Time-Dependent NO Production in EA.hy926 Cells}

DPHC (Figure 1a), a phlorotannin isolated from IO extract, constitutes $2.2 \% \pm 0.43$ of IO (Supplementary Materials). DPHC cytotoxicity in EA.hy926 cells is shown in Figure 1b. We found that DPHC was not toxic when used at concentrations of 6,20, and $60 \mu \mathrm{M}$, but upon treatment with $100 \mu \mathrm{M} \mathrm{DPHC}$, the cell viability was slightly decreased. Based on our previous study, we performed subsequent experiments with only non-toxic DPHC concentrations.

(a)

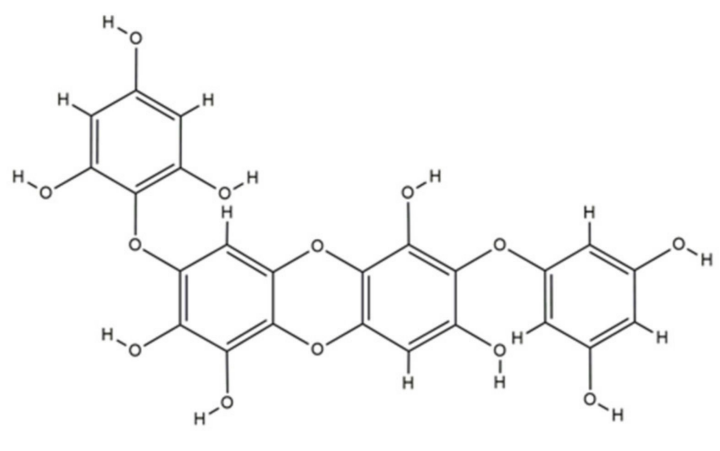

(b)

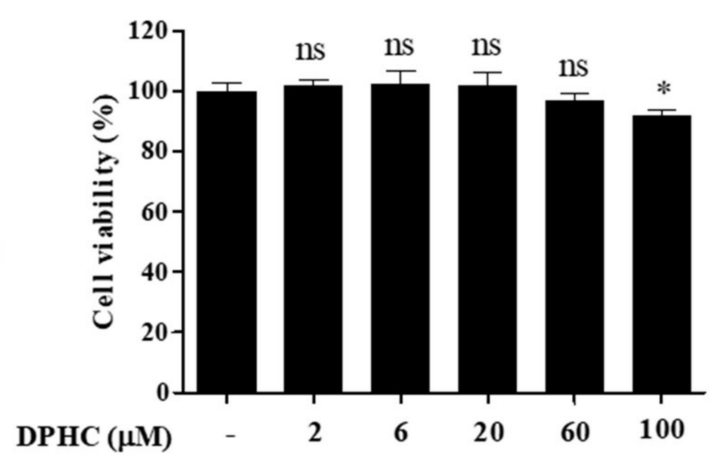

Figure 1. (a) Structure of diphlorethohydroxycarmalol (DPHC) (b) Cell viability analysis of EA.hy926 cells treated with different concentrations of DPHC. EA.hy926 cells were incubated with different concentrations of DPHC $(0,6,20,60$, and $100 \mu \mathrm{M}$ ) for $24 \mathrm{~h}$, and cell viability was determined by 3-(4-5-dimethyl-2yl)-2-5-diphynyltetrasolium bromide (MTT) assay. Each column and bar represent the mean \pm standard deviation (S.D.). ${ }^{*} p<0.05$, significant difference compared to the control group. DPHC: diphlorethohydroxycarmalol; ns: not significant.

NO production is dynamically correlated with concentrations of the stimulatory agent and the incubation time. Hence, we used the highest non-toxic concentration of DPHC $(60 \mu \mathrm{M})$ to investigate the optimal time for NO formation in EA.hy926 cells. We measured intracellular NO levels at five different time points ( $30 \mathrm{~min}, 1 \mathrm{~h}, 3 \mathrm{~h}, 12 \mathrm{~h}$, and $24 \mathrm{~h}$ ). NO production levels were significantly increased starting from $30 \mathrm{~min}$, and the peak was observed at $24 \mathrm{~h}$ (Figure 2a). Therefore, a 24-h incubation period was selected as the optimal incubation time for further experiments. Next, we investigated the levels of dose-dependent NO production in EA.hy926 cells treated with different concentrations 
of DPHC $(6,20,60$, and $100 \mu \mathrm{M})$. We observed that DPHC induced NO production in a dose-dependent pattern (Figure $2 \mathrm{~b}$ ). Of all the concentrations tested, the highest NO production was observed at 60 and $100 \mu \mathrm{M}$ of DPHC treatment.

(a)

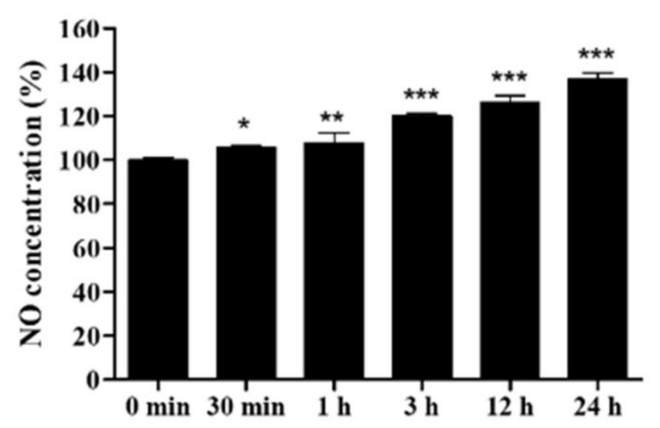

(b)

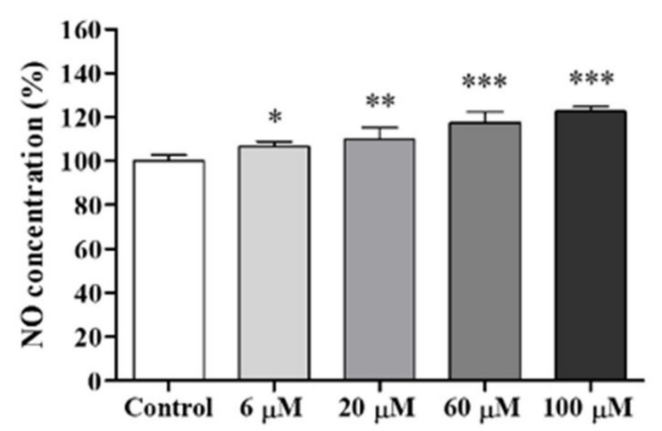

Figure 2. NO production in EA.hy926 cells treated with $60 \mu \mathrm{M}$ of diphlorethohydroxycarmalol (DPHC). (a) Levels of time-dependent NO production in EA.hy926 cells treated with $60 \mu \mathrm{M}$ of DPHC. (b) NO production in EA.hy926 cells induced by different concentrations of DPHC. Experiments were performed in triplicates. Each column and bar represent the mean \pm standard deviation (S.D.). ${ }^{*} p<0.05,{ }^{* *} p<0.01$. ${ }^{* * *} p<0.001$, significant difference compared to the control group.

\subsection{DPHC Promoted Phosphorylation in the PI3K/Akt/eNOS Pathway in EA.hy926 Cells}

Since phosphorylation of PI3K and Akt promotes eNOS activity and further enhances NO production [14], we evaluated whether the enhancement of NO production was related to this pathway; protein expression levels of $p$-PI3K, $p$-Akt, and $p$-eNOS were examined by Western blotting of EA.hy926 cells treated with different concentrations of DPHC. The relative levels of $p$-PI3K showed a dose-dependent increment (Figure 3b). However, the pattern showed a slight decrease from 60 to $100 \mu \mathrm{M}$. After checking the relative levels by statistical analyses, there was a non-significant difference between these two concentrations (data not shown). In addition, compared to the control group, the DPHC treatments remarkably enhanced $p$-Akt expression (Figure $3 \mathrm{c}$ ). The expression of $p$-eNOS showed a significant increment at 6, 20, and $60 \mu \mathrm{M}$ of DPHC compared to control (Figure $3 \mathrm{~d}$ ). Nevertheless, the expression of $p$-PI3K, $p$-Akt, and $p$-eNOS at $100 \mu \mathrm{M}$ of DPHC treatment showed a slightly decreased trend; the low cell viability was considered the main factor that affected the protein expression. Therefore, to eliminate the influence of cell viability, the $100 \mu \mathrm{M}$ concentration was excluded from further analyses. Based on these results, we hypothesized that DPHC might activate eNOS through the PI3K/Akt/eNOS signaling pathway.

\subsection{Regulatory Effects of DPHC on the $\left[\mathrm{Ca}^{2+}\right]_{\text {cytol }}$ and the $\left[\mathrm{Ca}^{2+}\right]_{E R}$ Levels}

In the present study, the $\left[\mathrm{Ca}^{2+}\right]_{\text {cytol }}$ level represented the calcium levels in the cytosol, which can be influenced by the activation of specific receptors such as vascular endothelial growth factor 2 (VEGFR2) and acetylcholine receptors (AchR). The $\left[\mathrm{Ca}^{2+}\right]_{\text {ER }}$ level represented calcium stored in the endoplasmic reticulum (ER). To investigate whether DPHC could upregulate $\left[\mathrm{Ca}^{2+}\right]$ levels in endothelial cells, $\left[\mathrm{Ca}^{2+}\right]_{\mathrm{ER}}$ and $\left[\mathrm{Ca}^{2+}\right]_{\text {cytol }}$ levels were measured separately. After treating the cells with $60 \mu \mathrm{M}$ of DPHC, $\left[\mathrm{Ca}^{2+}\right]_{\mathrm{ER}}$ levels were elevated after $20 \mathrm{~s}$ (Figure $4 \mathrm{a}$ ). We quantified the increase in $\left[\mathrm{Ca}^{2+}\right]_{\mathrm{ER}}$ levels by measuring the area under the curve (AUC). We found that $60 \mu \mathrm{M}$ of DPHC significantly raised $\left[\mathrm{Ca}^{2+}\right]_{\text {ER }}$ levels in EA.hy926 cells (Figure $4 \mathrm{~b}, p<0.001$ ). Moreover, $\left[\mathrm{Ca}^{2+}\right]_{\text {cytol }}$ levels were dramatically increased starting from $30 \mathrm{~s}$ after the treatment, with a peak detected around $60 \mathrm{~s}$. At $60 \mathrm{~s},\left[\mathrm{Ca}^{2+}\right]_{\mathrm{cytol}}$ levels were 1.75 times higher than that in the untreated control (Figure $4 \mathrm{c}$ ). Quantification of $\left[\mathrm{Ca}^{2+}\right]_{\text {cytol }}$ levels revealed that $60 \mu \mathrm{M}$ of DPHC significantly 
promoted an increase in the $\left[\mathrm{Ca}^{2+}\right]_{\text {cytol }}$ levels, compared to other DPHC concentrations (Figure $4 \mathrm{~d}, p<0.001$ ).

(a)

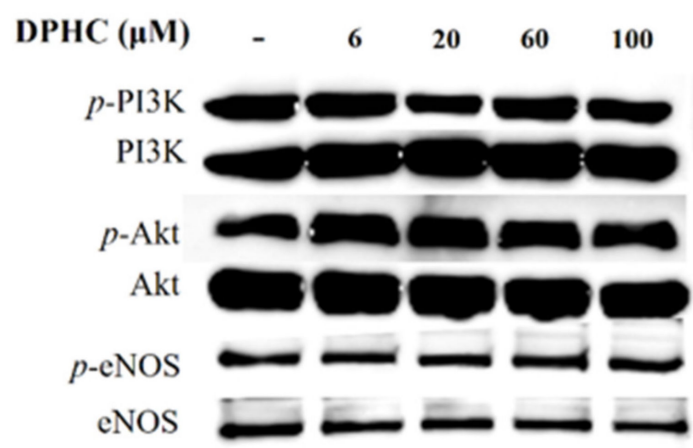

(c)

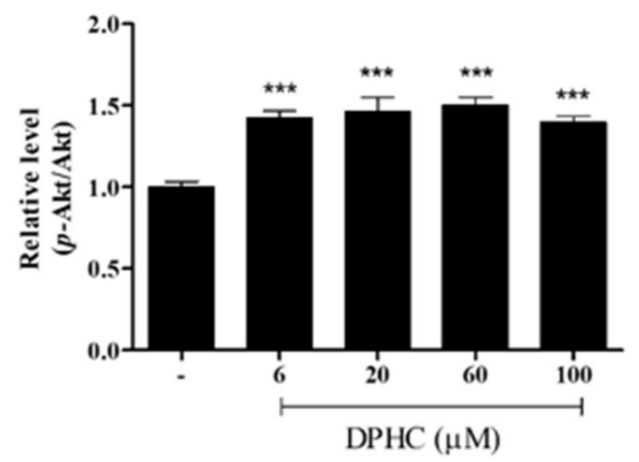

(b)

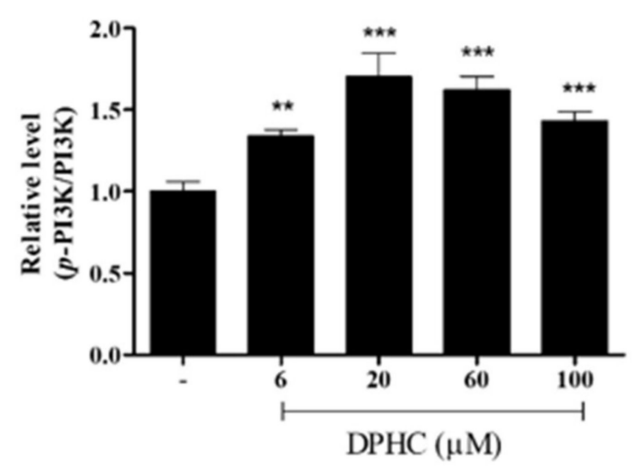

(d)

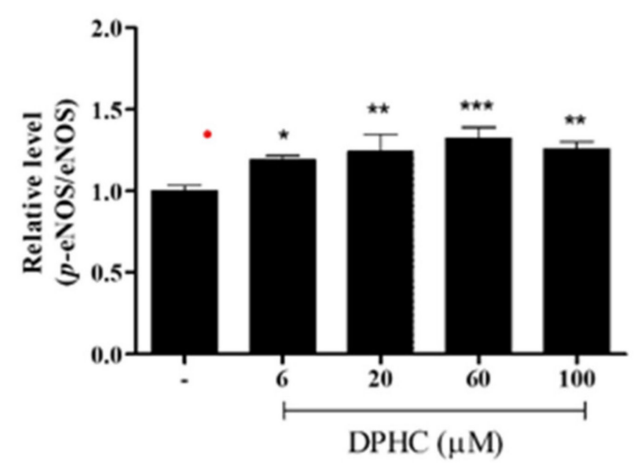

Figure 3. Evaluation of the expression levels of vasodilation-associated proteins. (a) Representative Western blot analysis. $(\mathbf{b}, \mathbf{c})$ Quantification of phosphorylated (p)-PI3K/PI3K (b), p-Akt/Akt (c), and p-eNOS/eNOS (d) in EA.hy926 cells treated with different concentrations of DPHC. The protein bands were ultimately developed and photographed with the FUSION Solo Vilber Lourmat system. Quantitative data were analyzed using Image J 1.50i software (NIH, USA). Results are expressed as the mean \pm standard deviation (S.D.) of three independent experiments. ${ }^{*} p<0.05,{ }^{* *} p<0.01$. ${ }^{* * *} p<0.001$, significant difference compared to the control group. DPHC: diphlorethohydroxycarmalol; PI3K: phosphoinositide 3-kinase; Akt: protein kinase B; eNOS: endothelial nitric oxide synthase.

\subsection{DPHC Modulated $\left[\mathrm{Ca}^{2+}\right]$ Levels by Activating AchR and VEGFR2}

$\left[\mathrm{Ca}^{2+}\right]$ levels can be influenced by the activation of VEGFR2 and AchR $[15,16]$. Thus, to investigate whether DPHC-induced NO formation was related to AchR and VEGFR2 activation, the respective specific antagonists, atropine and SU5416, were used. We tested different concentrations of atropine and SU5416 to attain the optimal inhibition conditions. Accordingly, a 2-h incubation with $60 \mu \mathrm{M}$ of atropine and $100 \mu \mathrm{M}$ of SU5416 showed the strongest inhibitory activity when administered separately. Therefore, the above concentrations were used in subsequent experiments. An increase in $\left[\mathrm{Ca}^{2+}\right]_{\text {cytol }}$ levels was only observed in the DPHC treatment group, with a maximal calcium concentration observed at about $30 \mathrm{~s}$ after treatment, followed by a gradual decline. As expected, $\left[\mathrm{Ca}^{2+}\right]_{\text {cytol }}$ levels were remarkably decreased when cells were treated with atropine and SU5416 compared to cells treated with DPHC. Additionally, there was no significant difference in $\left[\mathrm{Ca}^{2+}\right]_{\text {cytol }}$ levels between the antagonist-treated and control groups (Figure $5 \mathrm{a}, \mathrm{b}, p<0.001$ ). Thus, these findings indicate that the modulation of $\left[\mathrm{Ca}^{2+}\right]$ levels by DPHC was closely related to AchR and VEGFR2 activation. 
(a)

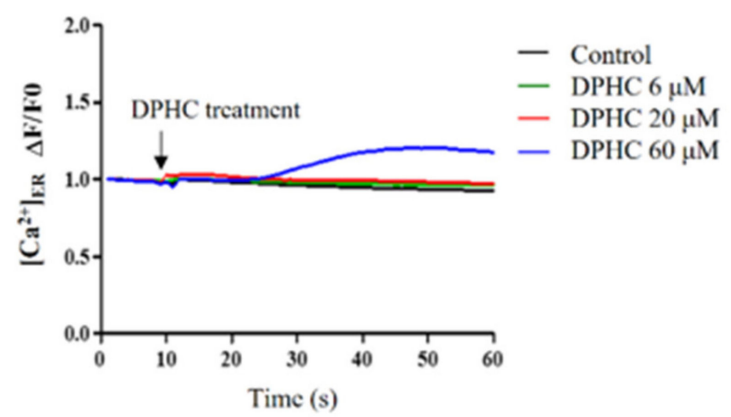

(c)

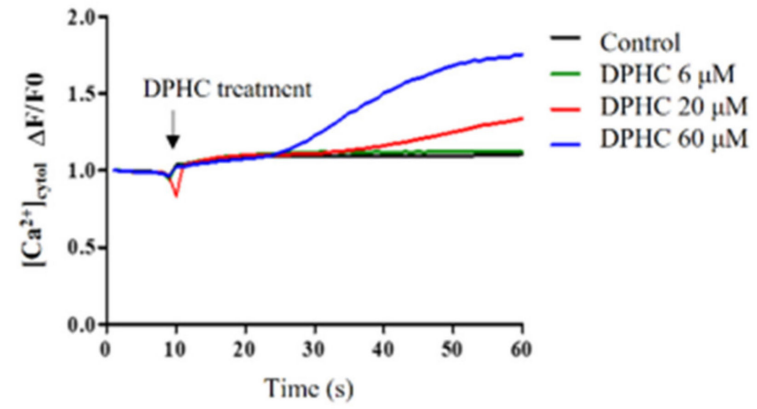

(b)

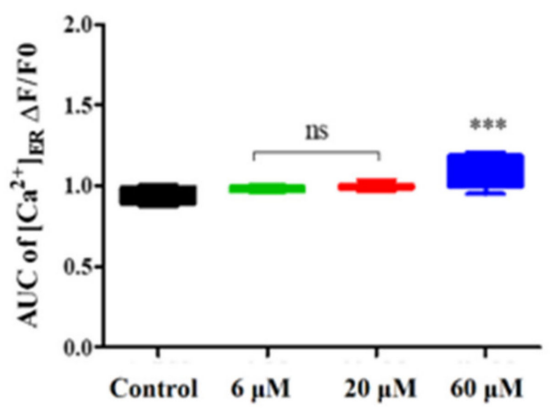

(d)

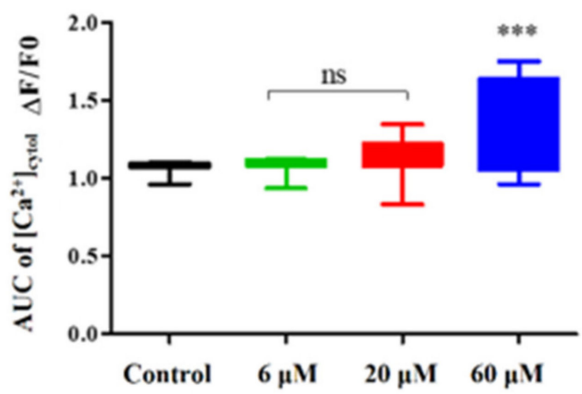

Figure 4. Quantification of the $\left[\mathrm{Ca}^{2+}\right]_{\mathrm{ER}}$ and $\left[\mathrm{Ca}^{2+}\right]_{\mathrm{cytol}}$ levels stimulated by different concentrations of DPHC in EA.hy926 cells. $(\mathbf{a}, \mathbf{b})$ The traces $(\mathbf{a})$ and box plots $(\mathbf{b})$ indicating the levels of $\left[\mathrm{Ca}^{2+}\right]_{\mathrm{ER}} \cdot(\mathbf{c}, \mathbf{d})$ The traces $(\mathbf{c})$ and box plots $(\mathbf{d})$ indicating the levels of $\left[\mathrm{Ca}^{2+}\right]_{\mathrm{cytol}}$. For statistical significance, each sample treatment group was compared to the control group. Experiments were performed in triplicates. ${ }^{*} p<0.05,{ }^{* *} p<0.01$, and ${ }^{* * *} p<0.001$. ns: not significant; AUC: area under the curve; DPHC: diphlorethohydroxycarmalol; $\left[\mathrm{Ca}^{2+}\right]_{\mathrm{ER}}$ : calcium level in the endoplasmic reticulum; $\left[\mathrm{Ca}^{2+}\right]_{\mathrm{cytol}}:$ calcium level in the cytosol; PSS: physiological salt solution.

Having found that $\left[\mathrm{Ca}^{2+}\right]$ levels could be regulated by AchR and VEGFR2 activation, we further hypothesized that $\left[\mathrm{Ca}^{2+}\right]$ levels would deeply influence NO production. To prove our hypothesis, cells were pretreated with atropine or SU5416 and incubated for $2 \mathrm{~h}$, followed by the addition of $60 \mu \mathrm{M}$ of DPHC. After $24 \mathrm{~h}$, intracellular NO concentrations were measured using 4 amino-5-methylamino-2', $7^{\prime}$-difluorescein diacetate (DAF-FM DA). We observed that both antagonists significantly suppressed NO formation upon DPHC stimulation (Figure 5c). Taken together, our results showed that the modulation of $\left[\mathrm{Ca}^{2+}\right]_{\text {cytol }}$ levels by AchR and VEGFR2 activation was sufficient and necessary for NO formation.

\subsection{DPHC Enhanced Vasodilation in the Tg(flk:EGFP) Transgenic Zebrafish}

Due to some characteristics, such as rapid development, ease of genetic manipulation, advanced genomic resources, as well as similar organ systems and gene functions as humans, the zebrafish (Danio rerio) provides significant advantages in terms of our understanding of cardiovascular disease causalities. Particularly, the embryos develop rapidly, exhibiting optical transparency during the first-hour post-fertilization, allowing for direct observation using light microscopy. These features contribute to the emergence of the zebrafish animal model as a useful and valuable tool for cardiovascular research $[17,18]$. To investigate whether DPHC could exert a vasodilation effect in vivo, we used a $T g$ (flk:eGFP) transgenic zebrafish model, in which the vascular endothelial cells are fluorescently stained with the enhanced green fluorescent protein (eGFP). After the treatment of samples, changes in the vessel diameter and the fluorescence intensity can be observed easily using confocal 
microscopy (Figure 6a). Zebrafish larvae were treated with different concentrations of DPHC $(0,0.06,0.2$, and $0.6 \mu \mathrm{M})$ from 3 days post fertilization (dpf) to $7 \mathrm{dpf}$. Treatment with $0.6 \mu \mathrm{M}$ of DPHC significantly increased the fluorescence intensity in the whole body compared to control larvae (Figure 6b). However, we did not observe any difference between the 0.06 and $0.2 \mu \mathrm{M}$ DPHC treatments.

(a)
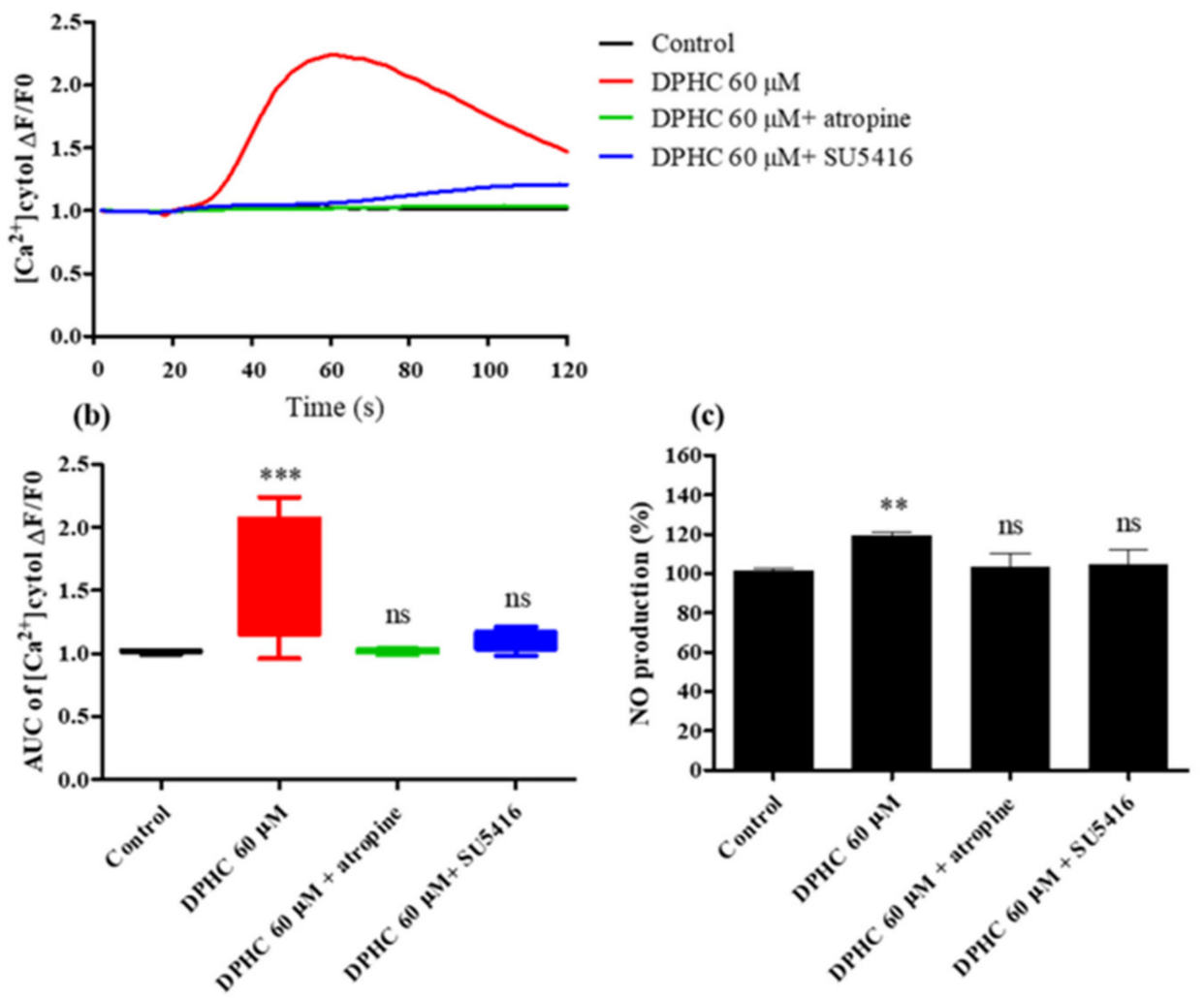

Figure 5. Influence of specific antagonists on $[\mathrm{Ca} 2+]_{\text {cytol }}$ levels in EA.hy926 cells treated with DPHC. $(\mathbf{a}, \mathbf{b})$ Traces $(\mathbf{a})$ and box plots (b) indicating [Ca2+] $]_{\text {cytol }}$ levels in response to treatment with DPHC $(60 \mu \mathrm{M})$ and antagonists. (c) Effect of DPHC on NO production in EA.hy926 cells pretreated with atropine or SU5416. The NO levels were detected by adding $10 \mu \mathrm{M}$ of 4 amino-5-methylamino-2', $7^{\prime}$-difluorescein diacetate (DAF-FM DA). Experiments were performed in triplicates. Each column and bar represent the mean \pm standard deviation (S.D.). ${ }^{* *} p<0.01 .{ }^{* * *} p<0.001$, significant difference compared to the control group. ns: not significant; AUC: area under the curve; DPHC: diphlorethohydroxycarmalol; [Ca2+] $]_{\text {cytol }}$ : calcium level in the cytosol.

Additionally, the dorsal aorta (DA) is the major trunk axial artery and is one of the first vessels to assemble in the early developmental stages in all vertebrates. A previous study demonstrated that the DA of the zebrafish acquires a vascular smooth muscle cellcontaining vascular wall similar to that found in other vertebrates. Therefore, evaluation of the DA diameter can be considered direct evidence for vasodilation. As shown in Figure 7, the DA diameter significantly increased with DPHC treatment $(0.06,0.2$, and $0.6 \mu \mathrm{M})$ compared to the control group. Therefore, our findings proved that DPHC could be a potential vasodilator. 
(a)

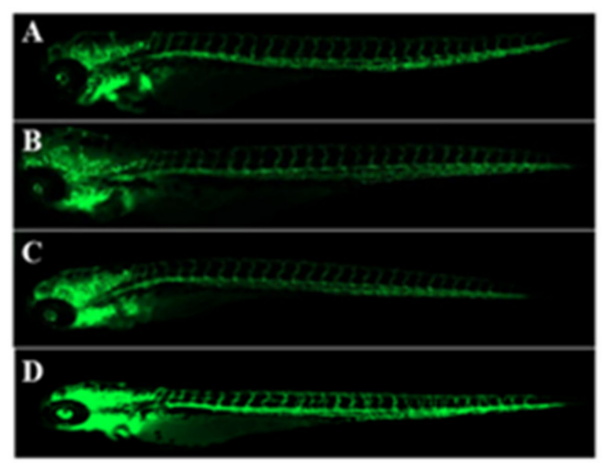

(b)

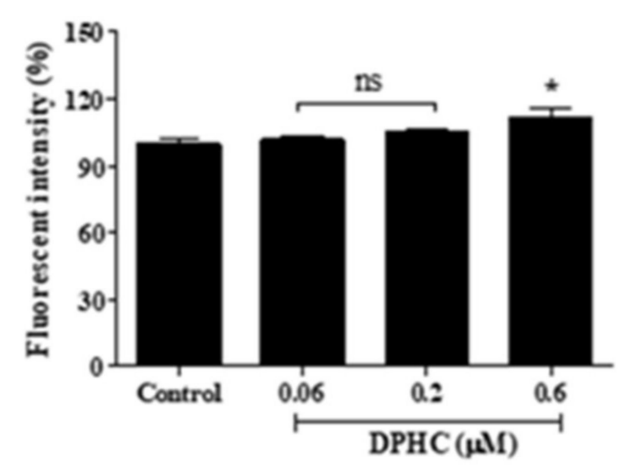

Figure 6. DPHC induces vasodilation in the whole-body vasculature in a Tg(flk:EGFP) transgenic zebrafish model. (a) Representative images of the $\mathrm{Tg}(\mathrm{flk}$ :EGFP) transgenic zebrafish larva's whole body captured using a fluorescence microscope $(4 \times)$. A: $0 \mu \mathrm{M}$ of DPHC (Control); B: $0.06 \mu \mathrm{M}$ of DPHC; C: $0.2 \mu \mathrm{M}$ of DPHC; D: $0.6 \mu \mathrm{M}$ of DPHC. (b) Quantification of the whole-body fluorescence intensity. Each column and bar represent the mean \pm standard deviation (S.D.), $n=8$ per group. ${ }^{*} p<0.05$, significant difference compared to the control group. ns: not significant; DPHC: diphlorethohydroxycarmalol.

(a)
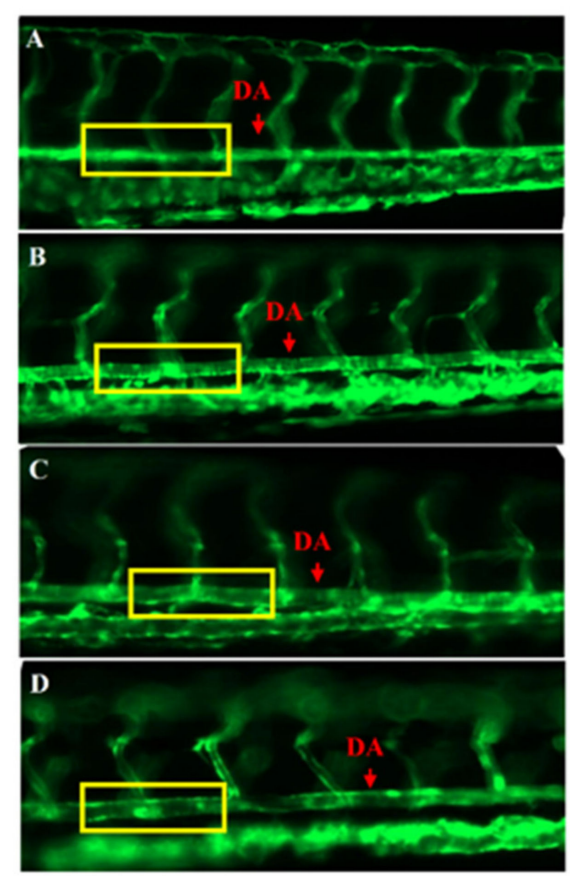

(b)

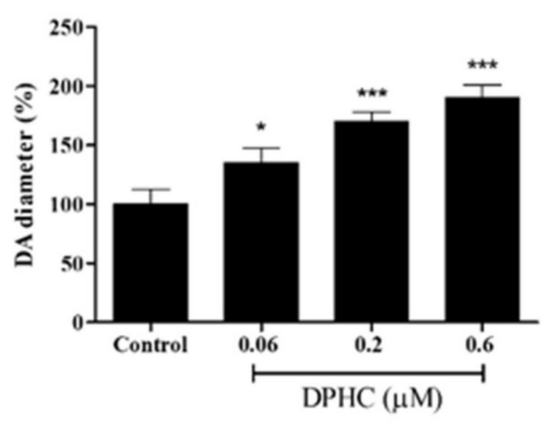

Figure 7. Vasodilation observed by changes in the vessel diameter in a Tg(flk:EGFP) transgenic zebrafish model. (a) Images of the vessel were captured using a fluorescence microscope $(20 \times)$. (A-D) Vasodilation observed by treatment with DPHC at $6 \mathrm{dpf}$. A: $0 \mu \mathrm{M}$ of DPHC (Control); B: $0.06 \mu \mathrm{M}$ of DPHC; C: $0.2 \mu \mathrm{M}$ of DPHC; D: $0.6 \mu \mathrm{M}$ of DPHC. (b) Measurement of the DA diameter. Each column and bar represents the mean \pm standard deviation (S.D.), $n=8$ per group. ${ }^{*} p<0.05,{ }^{* * *} p<0.001$, significant difference compared to the control group. DPHC: diphlorethohydroxycarmalol; DA: dorsal aorta.

\section{Discussion}

Several polyphenols extracted from terrestrial plants have been reported for their antihypertensive effects caused by increasing NO bioavailability and alleviation of vaso- 
constriction $[19,20]$. Marine algae are also a potentially rich resource of substances with beneficial health effects, but the molecular mechanisms underlying their effect on blood pressure are seldom known. Previous in vitro studies have reported that marine polyphenols isolated from Ecklonia Cava, such as phlorofucofuroeckol A, dieckol, and eckol, exert vasodilatory effects by increasing NO production and eNOS expression [21,22]. Furthermore, these polyphenols exhibited antihypertensive effects by decreasing the systolic blood pressure in hypertension mouse models [23]. In contrast, only protective effects against cardiovascular diseases, such as inhibition of diabetic disorders and obesity inhibition in 3T3-L1 adipocytes, have been reported for IO and DPHC [24]. The vasodilatory or antihypertensive properties of IO or DPHC were rarely mentioned. Therefore, we aimed to investigate the molecular mechanisms of vasodilation by DPHC using in vitro and in vivo models.

A concentration-dependent increase in NO production was observed in the DPHC treatment groups. It has been reported that multiple mechanisms control NO production via eNOS activation. First, the PI3K pathway members, including its downstream molecule, Akt, are essential regulators; activated Akt directly phosphorylates ser1177 on eNOS, enhancing the binding activity of $\left[\mathrm{Ca}^{2+}\right] /$ calmodulin [25]. Based on these aspects, we systematically examined protein expression in the PI3K/Akt/eNOS axis and measured calcium transit. Indeed, dose-dependent increments in PI3K, Akt, and eNOS were observed under DPHC treatment. Thus, we confirmed that DPHC-induced activation of the PI3K/Akt/eNOS pathway is essential in promoting NO formation in endothelial cells. Furthermore, activated eNOS promotes the binding of calcium ions to calmodulin, a multifunctional intermediate calcium-binding messenger protein. Once $\left[\mathrm{Ca}^{2+}\right]$ is bound to calmodulin, the $\left[\mathrm{Ca}^{2+}\right]$ signal transduction pathway is activated [26]. As such, calcium transit is also considered critical in NO generation [27]. Kida et al. indicated that increasing the $\left[\mathrm{Ca}^{2+}\right]_{\mathrm{ER}}$ level would activate the calmodulin-bound domain of eNOS, resulting in NO production [28]. Additionally, higher $\left[\mathrm{Ca}^{2+}\right]_{\text {cytol }}$ levels led to NO formation, which was shown in human umbilical vein endothelial cells [29]. In this study, we investigated the role of $\left[\mathrm{Ca}^{2+}\right]$ signaling under DPHC administration. After adding $60 \mu \mathrm{M}$ of DPHC, it was possible to detect a remarkable increase in $\left[\mathrm{Ca}^{2+}\right]_{\mathrm{cytol}}$ and $\left[\mathrm{Ca}^{2+}\right]_{\mathrm{ER}}$ levels after $30 \mathrm{~s}$, characterized by a $60 \mathrm{~s}$ oscillation peak phase. This increase was completely prevented by different antagonists (VEGFR2 and AchR antagonists). Theoretically, after the peak phase, a stabilization declining phase, also characterized by the presence of less intense and less frequent oscillations, would follow [30]. Nevertheless, within $60 \mathrm{~s}$, we did not observe any decreasing trend in $\left[\mathrm{Ca}^{2+}\right]_{\mathrm{cytol}}$ and $\left[\mathrm{Ca}^{2+}\right]_{\mathrm{ER}}$ levels (Figure $4 \mathrm{a}, \mathrm{c}$ ).

When the cells are stimulated, such as during membrane depolarization, extracellular signaling molecules or intracellular messengers enhance $\left[\mathrm{Ca}^{2+}\right]_{\text {cytol }}$ levels. This increment results from either an influx of $\left[\mathrm{Ca}^{2+}\right]$ from the outside of the cell via ion channels on the plasma membrane or the release of $\left[\mathrm{Ca}^{2+}\right]$ from internal stores (such as the ER). The increase in $\left[\mathrm{Ca}^{2+}\right]_{\text {cytol }}$ level is precipitous and is followed by a decline in $\left[\mathrm{Ca}^{2+}\right]$ levels, maintained by the homeostatic regulation of $\left[\mathrm{Ca}^{2+}\right]$ concentration [31]. Accordingly, having found that DPHC can effectively raise $\left[\mathrm{Ca}^{2+}\right]_{\mathrm{cytol}}$ and $\left[\mathrm{Ca}^{2+}\right]_{\mathrm{ER}}$ levels, we further focused on investigating how DPHC affects calcium regulation via cell membrane receptors (VEGFR2 and AchR). The muscarinic AchR family is divided into 5 subtypes: M1, M2, M3, M4, and M5 [32]. The activation of M3 receptors in vascular endothelial cells induces potent vasodilatation, and this process occurs via the release of an endothelium-derived relaxing factor, such as NO [33]. Ren et al. showed that acetylcholine induces vasodilatation by activating M3 receptors on endothelial and smooth muscle cells [34]. Moreover, AchR activation can induce a downstream pathway involved in the conversion of phosphatidylinositol biphosphate ( $\left.\mathrm{PIP}_{2}\right)$ into the two secondary messengers, inositol-1,4,5-trisphosphate $\left(\mathrm{IP}_{3}\right)$ and diacylglycerol (DAG), by phospholipase-C (PLC). $\mathrm{IP}_{3}$ diffuses into the cytosol and binds to its receptor (IP3R) on the ER, triggering the release of $\mathrm{Ca}^{2+}$ ions [35]. The rise of free $\mathrm{Ca}^{2+}$ ions mediates activation of $\mathrm{NO}$ generation via the phosphorylation of proteins, such as Akt and eNOS [36]. As we expected, the pretreatment of cells with atropine, a specific 
antagonist of AchR, completely blocked DPHC-induced rise in $\left[\mathrm{Ca}^{2+}\right]_{\text {cytol }}$. In addition, we observed that the level of NO was obviously suppressed by atropine. Therefore, we concluded that DPHC-induced rise in $\left[\mathrm{Ca}^{2+}\right]_{\mathrm{cytol}}$ and NO formation could proceed with AchR activation in EA.hy926 cells. Another potential regulator of vasodilation is VEGFR2, mainly expressed in the vascular endothelium [37]. When VEGF binds to VEGFR2, the receptor undergoes dimerization and phosphorylation of its tyrosine residues, triggering a downstream phosphorylation cascade targeting pro-angiogenic mediators [38]. Among the activated mediators are the PLC $\gamma 1 /$ calcium and PI3K/Akt/eNOS pathways [39]. Both pathways are associated with eNOS activation and NO synthesis. VEGFR2 data (Figure 5) demonstrated a similar trend with the AchR results. Treatment with $60 \mu \mathrm{M}$ of DPHC could not raise $\left[\mathrm{Ca}^{2+}\right]_{\text {cytol }}$ levels or NO production in EA.hy926 cells pretreated with SU5416. Therefore, we hypothesize that DPHC triggered an increase in $\left[\mathrm{Ca}^{2+}\right]_{\text {cytol }}$ levels by regulating AchR and VEGFR2 activation, resulting in NO production.

Based on the in vitro findings, we further examined the vasodilatory effect of DPHC in a transgenic zebrafish model. Compared to the mouse, zebrafish is a more economically feasible model for in vivo screening of small-molecule compounds in terms of cost-quality. Because the vascular structure is easily visualized, numerous studies on vascular-related disorders have been performed in different types of transgenic zebrafish models, such as angiogenesis [40], vasoconstriction [41], and diabetes-induced endothelial dysfunction models [42]. The $T g$ (flk:eGFP) transgenic zebrafish model is one of the most common strains for studying vessel diameter change. Once the vessel diameter is increased by sample treatment, a higher percentage of fluorescence intensity can be observed [12]. Therefore, the $T g(f l k: e G F P$ ) strain of zebrafish was employed in our in vivo experiments. As expected, treatment with $0.6 \mu \mathrm{M}$ of DPHC significantly increased the fluorescence intensity in the whole body of zebrafish larvae (Figure 6). In other words, data indicated that treatment with $0.6 \mu \mathrm{M}$ of DPHC could effectively promote vasodilation. Further, we demonstrated clear evidence of vessel diameter increment in DA vessels. As previously stated, the DA is directly connected to the heart; thus, the DA diameter is important in the modulation of heartbeats and blood circulation $[43,44]$. Our results provide proof that treatment with DPHC could dramatically enhance vasodilation in a dose-dependent manner in in vivo models (Figure 7). However, due to the limited equipment, other cardiovascular parameters, such as blood flow velocity and cardiac output, need to be confirmed by further experiments.

In summary, we demonstrated that DPHC, a natural compound, can be a potential endothelium-dependent vasodilator that acts by modulating calcium transit through AchR and VEGFR2, increasing endothelial-dependent NO production and resulting in vasodilation in the $T g(f l k: e G F P)$ transgenic zebrafish model.

\section{Materials and Methods}

\subsection{Reagents}

Dulbecco's modified Eagle's medium (DMEM) and penicillin/streptomycin solution were purchased from GIBCO (Grand Island, NY, USA). Fetal bovine serum (FBS) was obtained from Merck (Sacramento, CA, USA); dimethyl sulfoxide (DMSO) and 3(4-5-dimethyl-2yl)-2-5-diphynyltetrasolium bromide (MTT) were purchased from SigmaAldrich (St. Louis, MO, USA). The intracellular NO production was detected using DAF-FM DA (Thermo Fisher Scientific, Waltham, MA, USA); the total NO production was measured using the Griess assay (Promega Corporation, Madison, WI, USA). Calcium levels were quantified using Fluo-4-AM dye (1-[2-amino-5-(2,7-difluoro-6-hydroxy-3-oxo-9-xanthenyl) phenoxyl]-2-(2-amino-5-methylphenoxy) ethane- $\mathrm{N}, \mathrm{N}, \mathrm{N}^{\prime}, \mathrm{N}^{\prime}$-tetraacetic acid, pentaacetoxymethyl ester) (Thermo Fisher Scientific, Waltham, MA, USA ). Atropine, a specific AchR antagonist, was purchased from Sigma Aldrich. SU5416, a VEGFR2 inhibitor, was obtained from Tocris Bioscience (Bristol, UK). 


\subsection{DPHC Isolation}

DPHC isolation was performed as previously described [13]. In brief, IO leaves were collected from Jeju Island, South Korea. IO specimens were washed with running water to remove salt, sand, and epiphytes attached to the surface. Next, IO specimens were lyophilized and ground to obtain a dry powder. Dried IO powder was extracted in $50 \%$ ethanol under refluxing conditions. The extract was concentrated and freeze-dried (final yield: $87 \mathrm{~g}$ ). Centrifugal partition chromatography (CPC) (CPC240, Tokyo, Japan) was performed with a portion of the extract. The CPC solvent system was composed of a mixture of $n$-hexane, EtOAc, $\mathrm{MeOH}$, and $\mathrm{H}_{2} \mathrm{O}$. Further purification was performed using an HPLC system (Milford, Massachusetts, USA) equipped with a YMC-Pack ODS-A column (YMC Co., Ltd., Kyoto, Japan). The sample was eluted using an isocratic solvent system.

\subsection{Cell Culture and Cell Viability Analysis}

Human cardiovascular endothelial cell line EA.hy926 was acquired from the American Type Culture Collection (ATCC; Manassas, VA, USA) and cultured in DMEM supplemented with $100 \mathrm{U} / \mathrm{mL}$ penicillin, $0.1 \mathrm{mg} / \mathrm{mL}$ streptomycin, and $10 \% \mathrm{FBS}$. Cells were grown in a humidified incubator at $37^{\circ} \mathrm{C}$, in an atmosphere with $5 \%(v / v) \mathrm{CO}_{2}$. Cells at $2-5$ passages were used for all experiments.

EA.hy926 cell viability was assessed by an MTT assay. A total of $1 \times 10^{5}$ cells/well (180 $\mu \mathrm{L}$ of cell suspension) were seeded in a 96-well plate and incubated at $37^{\circ} \mathrm{C}$ for $24 \mathrm{~h}$. Cells were treated with different concentrations $(6,20$, and $60 \mu \mathrm{M})$ of DPHC for another $24 \mathrm{~h}$. Then, $100 \mu \mathrm{L}$ (concentration: $2 \mathrm{mg} / \mathrm{mL}$ ) of MTT was added to the wells, and cells were incubated for $2 \mathrm{~h}$. After $2 \mathrm{~h}$, the medium was replaced with $150 \mu \mathrm{L}$ of DMSO. The supernatant was collected, and the absorbance was measured using a microplate reader at 540 nm (Synergy HT, BioTek Instruments, Winooski, VT, USA).

\subsection{Quantification of the Intracellular NO Production}

DAF-FM DA is a fluorescent probe used to detect intracellular NO. DAF-FM DA is a cell-permeable deacetylated form of DAF-FM and is hydrolyzed by intracellular esterases to form a cell-impermeable DAF-FM that reacts with NO. Therefore, the fluorescence intensity in cells was used to evaluate intracellular NO levels [45]. EA.hy926 cells were pre-incubated with $10 \mu \mathrm{M}$ of DAF-FM DA reagent for $30 \mathrm{~min}$ in the dark. The mean fluorescence intensity was then measured using a spectrofluorometer (Synergy HT, BioTek Instruments, Italy).

\subsection{Quantification of the Intracellular and Extracellular Calcium Levels}

By definition, intracellular $\mathrm{Ca}^{2+}$ levels correspond to the concentration of calcium ions in the ER $\left(\left[\mathrm{Ca}^{2+}\right]_{\mathrm{ER}}\right)$, while the extracellular $\mathrm{Ca}^{2+}$ levels refer to the concentration of calcium ions in the cytosol $\left(\left[\mathrm{Ca}^{2+}\right]_{\text {cytol }}\right)$. Physiological salt solution (PSS) $(140 \mathrm{mM} \mathrm{NaCl}$, $5.9 \mathrm{mM} \mathrm{KCl}, 1.4 \mathrm{mM} \mathrm{MgCl} \cdot 6 \mathrm{H}_{2} \mathrm{O}_{2}, 10 \mathrm{mM}$ HEPES, $11.5 \mathrm{mM}$ glucose, $1.2 \mathrm{mM} \mathrm{NaH}_{2} \mathrm{PO}_{4}$, $5 \mathrm{mM} \mathrm{NaHCO}_{3}$, and $1.8 \mathrm{mM} \mathrm{CaCl}_{2}$, at $\mathrm{pH} 7.4$ with $\mathrm{NaOH}$ ) was used as the basal reagent. To measure $\left[\mathrm{Ca}^{2+}\right]_{\text {cytol }}$ levels, the $\mathrm{Ca}^{2+}$-sensitive Fluo-4 probe was dissolved in PSS. On the contrary, to measure $\left[\mathrm{Ca}^{2+}\right]_{\mathrm{ER}}$ levels, the Fluo-4 probe was dissolved in a modified version of PSS, without $\mathrm{CaCl}_{2}$. EA.hy926 cells were seeded in 96-well plates overnight when they reached approximately $80 \%$ confluence. Next, $1 \times$ Fluo- 4 was added, and cells were incubated for $30 \mathrm{~min}$ at $37^{\circ} \mathrm{C}$ in the dark. The cells were rinsed twice with $1 \times$ phosphatebuffered saline (PBS), and $50 \mu \mathrm{L}$ of $1 \times$ PBS was added to the wells. Fluorescence intensity was measured for $10 \mathrm{~s}$ at 1 -s intervals. The cells were then treated with $1 \times$ PSS (Control) or DPHC at different concentrations $(6,20$, and $60 \mu \mathrm{M})$ dissolved in $0.1 \%$ bovine serum albumin (BSA). After the treatment, fluorescence was detected for another $50 \mathrm{~s}$ at 1-s intervals. To investigate the relationship between DPHC and either AchR or VEGFR2 activation, cells were pretreated for $2 \mathrm{~h}$ with $60 \mu \mathrm{M}$ of atropine, an AchR antagonist, and $100 \mu \mathrm{M}$ of SU5416, a VEGFR2 antagonist. The $1 \times$ Fluo- 4 fluorescent dye was added, and cells were incubated for another $30 \mathrm{~min}$ at $37^{\circ} \mathrm{C}$ in the dark. Calcium levels were then 
measured as described earlier. The box plot data represent the mean value of the AUC calculated from 0 to $60 \mathrm{~s}$. The error bars indicate the maximum and minimum values.

\subsection{Western Blot Analysis}

EA.hy926 cells were treated with different concentrations $(0,6,20$, and $60 \mu \mathrm{M})$ of DPHC. After $24 \mathrm{~h}$, cells were washed and harvested with ice-cold PBS and lysed with a lysis buffer on ice for $1 \mathrm{~h}$. Lysates were centrifuged at 12,000 rpm for $20 \mathrm{~min}$, and the protein concentration in the supernatant was evaluated with a BSA protein assay kit (Bio-Rad, Hercules, CA, USA). Next, sodium dodecyl sulfate-polyacrylamide gel electrophoresis (SDS-PAGE) was performed with $10 \%$ gel. Proteins were transferred onto a nitrocellulose membrane. Membranes were incubated at $4{ }^{\circ} \mathrm{C}$ overnight with the following primary antibodies added separately: anti- $\beta$-actin (sc-47778, Santa Cruz Biotechnology, CA, USA; 1:1000), anti-p-AKT (sc-377556, Santa Cruz Biotechnology; 1:1000), anti-p-eNOS (\#9571S, Cell Signaling Technology, Danvers, Massachusetts, USA; 1:1000), and anti- $p$-PI3K (\#17366S, Cell Signaling Technology; 1:1000) dissolved in 5\% skim milk. Immunoblots were incubated for another $2 \mathrm{~h}$ at room temperature with specific secondary antibodies (1:3000). Protein bands were ultimately developed and photographed using the FUSION SOLO Vilber Lourmat system, Paris, France. The Image J 1.50i software (NIH, USA) was used for quantifying the band intensities.

\subsection{Maintenance and Fluorescence Intensity Assessment in the Tg(flk:EGFP) Transgenic Zebrafish}

The zebrafish experiment received approval from the Animal Care and Use Committee of Jeju National University (Approval No. 2017-0001). The Tg(flk:EGFP) zebrafish model was used to investigate the behavior of endothelial cells in vivo. Fish were housed in 3-L tanks (Aquatic Habitats, Apopka, FL) containing buffered water ( $\mathrm{pH} 7.5$ ) maintained at $28.5^{\circ} \mathrm{C}$. Fertilized eggs were collected from the bottom of the tank in water (temperature $28.5^{\circ} \mathrm{C}, \mathrm{pH} 7.5$, dissolved oxygen 7.0 , and conductivity $800 \mu \mathrm{S}$ ) containing methylene blue and were placed in Petri dishes after being washed thoroughly with water and transferred to the incubator. For all the experimental procedures, larvae were maintained in 24-well plates containing egg water (reverse osmosis water containing $60 \mathrm{mg}$ sea salt per liter of water, pH 7.5). Larvae were treated with $0,0.06,0.2$, and $0.6 \mu \mathrm{M}$ of DPHC at $3 \mathrm{dpf}$. After six days of treatment, larvae were photographed using a fluorescence microscope at $4 \times$ magnification to capture blood vessels in the whole body. Fluorescence intensity signals of the whole body were measured using the Gen5 3.04 software (Bioteck). Fluorescence images were imported into the Image J software to calculate the corrected total object fluorescence (CTOF), according to the following formula:

$\mathrm{CTOF}=$ Integrated density $-($ Area of selected object $\times$ mean background fluorescence $)$

\subsection{Statistical Analysis}

All experiments were conducted in triplicates, and data are shown as mean \pm standard deviation. Statistical analysis was performed using the one-way analysis of variance (ANOVA) with Dunnett's post hoc test with the Prism 5.0 software (GraphPad Software, La Jolla, CA, USA). The following $p$-values were considered statistically significant, and they have been illustrated with asterisks in all figures: ${ }^{*} p<0.05$, ${ }^{* *} p<0.01$, and ${ }^{* * *} p<0.001$.

\section{Conclusions}

In this study, we demonstrated the molecular mechanisms underlying the vasodilatory effect of the marine polyphenol, DPHC. DPHC promoted endothelium-dependent vasodilation by modulating calcium concentration through AchR and VEGFR2 activation, thereby triggering NO synthesis through activation of the PI3K/Akt/eNOS pathway. Therefore, DPHC is a potential novel natural compound for vasodilation and the prevention of endothelium-dependent cardiovascular diseases. 
Supplementary Materials: The following are available online at https:/ /www.mdpi.com/1422-006 7/22/4/1610/s1.

Author Contributions: Conceptualization, Y.A.L. and B.R.; methodology, Y.A.L., Y.J., H.-W.Y., and J.H.; software, Y.A.L.; validation, Y.A.L.; formal analysis, Y.A.L.; investigation Y.A.L.; resources, Y.J.; data curation, Y.A.L.; writing-original draft preparation, Y.A.L.; writing-review and editing, B.R.; supervision, Y.-J.J.; project administration, Y.-J.J.; funding acquisition, Y.-J.J. All authors have read and agreed to the published version of the manuscript.

Funding: This research was supported by a part of the project titled 'Development of functional food products with natural materials derived from marine resources (no. 20170285),' funded by the Ministry of Oceans and Fisheries, Korea.

Institutional Review Board Statement: The study was conducted according to the guidelines of the Animal Care and Use Committee of Jeju National University (Approval No. 2017-0001).

Informed Consent Statement: Not applicable.

Data Availability Statement: The data sets generated and/or analyzed during the current study are available from the corresponding author on a reasonable request.

Acknowledgments: The authors would like to thank Dong-Min Chung and Shinwoo Co. Ltd. (Korea) for their assistance in preparing IO extract.

Conflicts of Interest: The authors declare no conflict of interest.

\section{References}

1. Gómez-Guzmán, M.; Toral, M.; Romero, M.; Jiménez, R.; Galindo, P.; Sánchez, M.; Zarzuelo, M.J.; Olivares, M.; Gálvez, J.; Duarte, J. Antihypertensive effects of probiotics lactobacillus strains in spontaneously hypertensive rats. Mol. Nutr. Food Res. 2015, 59, 2326-2336. [CrossRef] [PubMed]

2. Carrizzo, A.; Ambrosio, M.; Damato, A.; Madonna, M.; Storto, M.; Capocci, L.; Campiglia, P.; Sommella, E.; Trimarco, V.; Rozza, F.; et al. Morus alba extract modulates blood pressure homeostasis through enos signaling. Mol. Nutr. Food Res. 2016, 60, $2304-2311$. [CrossRef] [PubMed]

3. Robles-Vera, I.; Toral, M.; de la Visitación, N.; Sánchez, M.; Romero, M.; Olivares, M.; Jiménez, R.; Duarte, J. The probiotic lactobacillus fermentum prevents dysbiosis and vascular oxidative stress in rats with hypertension induced by chronic nitric oxide blockade. Mol. Nutr. Food Res. 2018, 62, 1800298. [CrossRef] [PubMed]

4. Li, X.; Dai, Y.; Yan, S.; Shi, Y.; Li, J.; Liu, J.; Cha, L.; Mu, J. Resveratrol lowers blood pressure in spontaneously hypertensive rats via calcium-dependent endothelial no production. Clin. Exp. Hypertens. 2016, 38, 287-293. [CrossRef] [PubMed]

5. Zhao, Y.; Vanhoutte, P.M.; Leung, S.W.S. Vascular nitric oxide: Beyond enos. J. Pharmacol. Sci. 2015, 129, 83-94. [CrossRef]

6. Leung, W.K.; Gao, L.; Siu, P.M.; Lai, C.W. Diabetic nephropathy and endothelial dysfunction: Current and future therapies, and emerging of vascular imaging for preclinical renal-kinetic study. Life Sci. 2016, 166, 121-130. [CrossRef] [PubMed]

7. Nagpure, B.V.; Bian, J.S. Interaction of hydrogen sulfide with nitric oxide in the cardiovascular system. Oxid. Med. Cell Longev. 2016, 2016, 6904327. [CrossRef] [PubMed]

8. Bernatova, I. Endothelial dysfunction in experimental models of arterial hypertension: Cause or consequence? Biomed. Res. Int. 2014, 2014, 598271. [CrossRef] [PubMed]

9. Gheibi, S.; Jeddi, S.; Kashfi, K.; Ghasemi, A. Regulation of vascular tone homeostasis by no and h2s: Implications in hypertension. Biochem. Pharm. 2018, 149, 42-59. [CrossRef] [PubMed]

10. Fernando, I.P.S.; Ryu, B.; Ahn, G.; Yeo, I.-K.; Jeon, Y.-J. Therapeutic potential of algal natural products against metabolic syndrome: A review of recent developments. Trends Food Sci. Technol. 2020, 97, 286-299. [CrossRef]

11. Lee, K.M.; Yang, E.C.; Coyer, J.A.; Zuccarello, G.C.; Wang, W.-L.; Choi, C.G.; Boo, S.M. Phylogeography of the seaweed ishige okamurae (phaeophyceae): Evidence for glacial refugia in the northwest pacific region. Mar. Biol. 2012, 159, 1021-1028. [CrossRef]

12. Fernando, K.; Yang, H.-W.; Jiang, Y.; Jeon, Y.-J.; Ryu, B. Ishige okamurae extract and its constituent ishophloroglucin a attenuated in vitro and in vivo high glucose-induced angiogenesis. Int. J. Mol. Sci. 2019, 20, 5542. [CrossRef]

13. Fernando, K.H.N.; Yang, H.W.; Jiang, Y.; Jeon, Y.J.; Ryu, B. Diphlorethohydroxycarmalol isolated from ishige okamurae represses high glucose-induced angiogenesis in vitro and in vivo. Mar. Drugs 2018, 16, 375. [CrossRef] [PubMed]

14. De Oliveira, T.S.; de Oliveira, L.M.; de Oliveira, L.P.; Costa, R.M.D.; Tostes, R.C.; Georg, R.C.; Costa, E.A.; Lobato, N.S.; Filgueira, F.P.; Ghedini, P.C. Activation of PI3K/Akt pathway mediated by estrogen receptors accounts for estrone-induced vascular activation of cgmp signaling. Vasc. Pharm. 2018, 110, 42-48. [CrossRef] [PubMed]

15. Radu, B.M.; Osculati, A.M.M.; Suku, E.; Banciu, A.; Tsenov, G.; Merigo, F.; Di Chio, M.; Banciu, D.D.; Tognoli, C.; Kacer, P.; et al. All muscarinic acetylcholine receptors (M1-M5) are expressed in murine brain microvascular endothelium. Sci. Rep. 2017, 7, 5083. [CrossRef] [PubMed] 
16. McFadzean, I.; Gibson, A. The developing relationship between receptor-operated and store-operated calcium channels in smooth muscle. Br. J. Pharmacol. 2002, 135, 1-13. [CrossRef]

17. Sun, G.; Liu, K. Developmental toxicity and cardiac effects of butyl benzyl phthalate in zebrafish embryos. Aquat. Toxicol. 2017, 192, 165-170. [CrossRef]

18. Giardoglou, P.; Beis, D. On zebrafish disease models and matters of the heart. Biomedicines 2019, 7, 15. [CrossRef]

19. Hügel, H.M.; Jackson, N.; May, B.; Zhang, A.L.; Xue, C.C. Polyphenol protection and treatment of hypertension. Phytomedicine 2016, 23, 220-231. [CrossRef]

20. Khurana, S.; Venkataraman, K.; Hollingsworth, A.; Piche, M.; Tai, T.C. Polyphenols: Benefits to the cardiovascular system in health and in aging. Nutrients 2013, 5, 3779-3827. [CrossRef]

21. Wijesinghe, W.; Ko, S.-C.; Jeon, Y.-J. Effect of phlorotannins isolated from ecklonia cava on angiotensin i-converting enzyme (ace) inhibitory activity. Nutr. Res. Pract. 2011, 5, 93-100. [CrossRef] [PubMed]

22. Gómez-Guzmán, M.; Rodríguez-Nogales, A.; Algieri, F.; Gálvez, J. Potential role of seaweed polyphenols in cardiovascularassociated disorders. Mar. Drugs 2018, 16, 250. [CrossRef]

23. Ko, S.-C.; Kang, M.C.; Kang, N.; Kim, H.-S.; Lee, S.-H.; Ahn, G.; Jung, W.-K.; Jeon, Y.-J. Effect of angiotensin i-converting enzyme (ace) inhibition and nitric oxide (no) production of 6,6'-bieckol, a marine algal polyphenol and its anti-hypertensive effect in spontaneously hypertensive rats. Process Biochem. 2017, 58, 326-332. [CrossRef]

24. Kang, M.C.; Ding, Y.; Kim, H.S.; Jeon, Y.J.; Lee, S.H. Inhibition of adipogenesis by diphlorethohydroxycarmalol (dphc) through ampk activation in adipocytes. Mar. Drugs 2019, 17, 44. [CrossRef] [PubMed]

25. Dudzinski, D.M.; Michel, T. Life history of enos: Partners and pathways. Cardiovasc. Res. 2007, 75, 247-260. [CrossRef]

26. Long, Y.; Xia, J.-Y.; Chen, S.-W.; Gao, C.-L.; Liang, G.-N.; He, X.-M.; Wu, J.; Jiang, C.-X.; Liu, X.; Huang, W.; et al. Atp2b1 gene silencing increases insulin sensitivity through facilitating akt activation via the $\mathrm{ca}(2+) /$ calmodulin signaling pathway and ca(2+)-associated enos activation in endothelial cells. Int. J. Biol. Sci. 2017, 13, 1203-1212. [CrossRef]

27. Guizoni, D.M.; Vettorazzi, J.F.; Carneiro, E.M.; Davel, A.P. Modulation of endothelium-derived nitric oxide production and activity by taurine and taurine-conjugated bile acids. Nitric Oxide 2020, 94, 48-53. [CrossRef]

28. Kida, T.; Tsubosaka, Y.; Hori, M.; Ozaki, H.; Murata, T. Bile acid receptor tgr5 agonism induces no production and reduces monocyte adhesion in vascular endothelial cells. Arterioscler. Thromb. Vasc. Biol. 2013, 33, 1663-1669. [CrossRef]

29. Nakajima, T.; Okuda, Y.; Chisaki, K.; Shin, W.-S.; Iwasawa, K.; Morita, T.; Matsumoto, A.; Suzuki, J.-I.; Suzuki, S.; Yamada, N.; et al. Bile acids increase intracellular $\mathrm{Ca} 2+$ concentration and nitric oxide production in vascular endothelial cells. Br. J. Pharmacol. 2000, 130, 1457-1467. [CrossRef]

30. Martinotti, S.; Patrone, M.; Balbo, V.; Mazzucco, L.; Ranzato, E. Endothelial response boosted by platelet lysate: The involvement of calcium toolkit. Int. J. Mol. Sci. 2020, 21, 808. [CrossRef] [PubMed]

31. Bagur, R.; Hajnóczky, G. Intracellular Ca2+ sensing: Its role in calcium homeostasis and signaling. Mol. Cell 2017, 66, 780-788. [CrossRef] [PubMed]

32. Martinez-Archundia, M.; Cordomi, A.; Garriga, P.; Perez, J.J. Molecular modeling of the m3 acetylcholine muscarinic receptor and its binding site. J. Biomed. Biotechnol. 2012, 2012, 789741. [CrossRef]

33. Touyz, R.M.; Alves-Lopes, R.; Rios, F.J.; Camargo, L.L.; Anagnostopoulou, A.; Arner, A.; Montezano, A.C. Vascular smooth muscle contraction in hypertension. Cardiovasc. Res. 2018, 114, 529-539. [CrossRef] [PubMed]

34. Ren, L.M.; Nakane, T.; Chiba, S. Muscarinic receptor subtypes mediating vasodilation and vasoconstriction in isolated, perfused simian coronary arteries. J. Cardiovasc. Pharmacol. 1993, 22, 841-846. [CrossRef]

35. Brown, P.T.; Herbert, P.; Woodruff, R.I. Vitellogenesis in oncopeltus fasciatus: Plc/ip3, dag/pk-c pathway triggered by cam. J. Insect Physiol. 2010, 56, 1300-1305. [CrossRef]

36. Zhang, W.; Sun, R.; Zhong, H.; Tang, N.; Liu, Y.; Zhao, Y.; Zhang, T.; He, F. Casr participates in the regulation of vascular tension in the mesentery of hypertensive rats via the plc-ip3/ac-v/camp/ras pathway. Mol. Med. Rep. 2019, 20, 4433-4448. [CrossRef] [PubMed]

37. Pandey, A.K.; Singhi, E.K.; Arroyo, J.P.; Ikizler, T.A.; Gould, E.R.; Brown, J.; Beckman, J.A.; Harrison, D.G.; Moslehi, J. Mechanisms of vegf (vascular endothelial growth factor) inhibitor-associated hypertension and vascular disease. Hypertension 2018, 71, e1-e8. [CrossRef]

38. Tao, B.B.; Liu, S.Y.; Zhang, C.C.; Fu, W.; Cai, W.J.; Wang, Y.; Shen, Q.; Wang, M.J.; Chen, Y.; Zhang, L.J.; et al. Vegfr2 functions as an h2s-targeting receptor protein kinase with its novel cys1045-cys1024 disulfide bond serving as a specific molecular switch for hydrogen sulfide actions in vascular endothelial cells. Antioxid. Redox Signal. 2013, 19, 448-464. [CrossRef] [PubMed]

39. Bencze, M. The role of calcium influx and calcium sensitization in contraction of isolated arteries of normotensive and hypertensive rat. 2017. Available online: https://dspace.cuni.cz/handle/20.500.11956/96364 (accessed on 5 February 2021).

40. Vimalraj, S.; Pichu, S.; Pankajam, T.; Dharanibalan, K.; Djonov, V.; Chatterjee, S. Nitric oxide regulates intussusceptive-like angiogenesis in wound repair in chicken embryo and transgenic zebrafish models. Nitric Oxide 2019, 82, 48-58. [CrossRef] [PubMed]

41. Margiotta-Casaluci, L.; Owen, S.F.; Rand-Weaver, M.; Winter, M.J. Testing the translational power of the zebrafish: An interspecies analysis of responses to cardiovascular drugs. Front. Pharm. 2019, 10, 893. [CrossRef] [PubMed]

42. Wiggenhauser, L.M.; Kroll, J. Vascular damage in obesity and diabetes: Highlighting links between endothelial dysfunction and metabolic disease in zebrafish and man. Curr. Vasc. Pharmacol. 2019, 17, 476-490. [CrossRef] 
43. Fritsche, R.; Schwerte, T.; Pelster, B. Nitric oxide and vascular reactivity in developing zebrafish, danio rerio. Am. J. Physiol. Regul. Integr. Comp. Physiol. 2000, 279, R2200-R2207. [CrossRef] [PubMed]

44. Bahrami, N.; Childs, S.J. Development of vascular regulation in the zebrafish embryo. Development 2020, 147, dev183061. [CrossRef] [PubMed]

45. Caruso, G.; Fresta, C.G.; Siegel, J.M.; Wijesinghe, M.B.; Lunte, S.M. Microchip electrophoresis with laser-induced fluorescence detection for the determination of the ratio of nitric oxide to superoxide production in macrophages during inflammation. Anal. Bioanal. Chem. 2017, 409, 4529-4538. [CrossRef] [PubMed] 